\title{
Revisão sistemática da literatura sobre as causas de evasão da Educação a Distância no Brasil
}

\author{
Caroline Victória Silva Barbosa de Oliveira ${ }^{1}$ \\ Diogo Henrique Duarte Bezerra ${ }^{2}$ \\ Glauce Viana de Souza Torres ${ }^{3}$
}

\section{RESUMO}

Este artigo apresenta uma revisão sistemática de literatura com o objetivo de identificar as causas de evasão na modalidade de Educação a Distância no Brasil. Para tal, o estudo buscou artigos que abordassem as causas da evasão na Educação a Distância em instituições de ensino do país. Ao todo, foram selecionados e analisados 40 artigos por meio de meta-análise de natureza quantitativa. Os resultados obtidos apontam que as causas de evasão são classificadas como exógenas e endógenas. $O$ estudo indica que é necessário um processo contínuo de autoavaliação no curso, especialmente, das atribuições dos atores nesse processo e da gestão do vínculo semestral dos acadêmicos em curso, sobretudo o acompanhamento do ensino e aprendizagem e as melhorias contínuas dos processos entre os atores na modalidade a distância, a fim de se evitar a evasão.

Palavras-chave: Causas de Evasão. Educação a Distância. EaD.

\footnotetext{
${ }^{1}$ carolinevsboliveira@gmail.com - Universidade Federal do Mato Grosso

2 diogo@ufmt.br - Universidade Federal do Mato Grosso

${ }^{3}$ glauce.ufmt@gmail.com - Universidade Federal do Mato Grosso
} 


\section{Systematic review of the literature on the causes of Distance Education evasion in Brazil}

\section{ABSTRACT}

This article presents a systematic review of the literature in order to identify the causes of evasion in the distance learning modality in Brazil. To this end, the study sought articles that addressed the causes of evasion in distance education in educational institutions in the country, in all 40 articles were selected and analyzed through a quantitative meta-analysis. The results obtained indicate that the causes of evasion are classified as exogenous and endogenous. The study points out that a continuous process of self-assessment in the course is necessary, especially the attributions of the actors in the process, the semiannual link management of the students in progress, especially the monitoring of teaching and learning and the continuous improvement of processes among the actors in the modality a distance, can culminate in evasion.

Keywords: Causes of Evasion. Distance Education. EaD. 
A modalidade de Educação a Distância (EaD) no Brasil, considerando os relatos científicos da última década, enfrenta problemas relacionados à evasão dos estudantes em seus cursos. A evasão é a desistência ou abandono, pelo estudante, de um curso ou programa de ensino sem concluí-lo (ASHBY, 2004).

De acordo com o censo da Associação Brasileira da Educação a Distância (ABED), as taxas de evasão de $22 \%$ dos cursos regulamentados totalmente a distância foram de $26 \%$ a 50\%, e cerca de $18,5 \%$ dos outros cursos tinham taxas de evasão entre $21 \%$ e $25 \%$. Esses dados mostram que a evasão segue sendo uma problemática na Educação a Distância. (ABED, 2019)

As evasões causam problemas às instituições de ensino, sejam públicas ou privadas, como: a ausência de retornos sociais e financeiros a partir dos investimentos realizados; a ociosidade dos colaboradores - professores e funcionários -; e a utilização limitada de toda a infraestrutura necessária para a oferta e operação dos cursos (BALTAR; SILVA, 2019; BITTENCOURT; MERCADO, 2014).

Sendo assim, há uma preocupação dos gestores das instituições de ensino por esse fenômeno, pois também é um problema causado pela falta do gerenciamento eficiente dos cursos na modalidade de EaD (BRUNO-FARIA; FRANCO, 2012). Além dos gestores, os pesquisadores também têm interesse pela temática, buscando compreender as causas que levam os estudantes a evadirem de seus respectivos cursos (MARTINS; GEBRAN; TEÇARIOL, 2014).

Nessa busca de uma compreensão mais profunda e métodos para uma melhor gestão dos cursos quanto ao problema da evasão, alguns trabalhos apresentam propostas de modelos e aplicações de técnicas para a previsão da evasão na EaD, como a mineração de dados, o aprendizado de máquina e os sistemas multiagentes (AMORIM; BARONE; MANSUR, 2008; LIRA et al., 2016; QUEIROGA; CECHINEL; ARAÚJO, 2017; QUEIROGA et al., 2018; RIGO; BARBOSA; CAMBRUZZI, 2014).

A revisão sistemática realizada por este trabalho foi motivada por um projeto de pesquisa que tem o objetivo de criar uma inteligência artificial capaz de prever e informar aos docentes e gestores, a possibilidade de evasão de um estudante em um curso a distância. Para tal criação, há necessidade de se conhecer bem as causas da evasão na Educação a Distância.

Assim, os autores observaram que há dezenas de trabalhos empíricos na literatura sobre a evasão nas instituições de ensino que ofertam cursos na modalidade de Educação a Distância. Atualmente, entretanto, há poucas revisões que reuniram um número considerável de trabalhos sobre causas de evasão na EaD e realizaram análises sistemáticas sobre as suas conclusões.

Este artigo apresenta uma revisão sistemática da literatura sobre a evasão em cursos ofertados na modalidade de Educação a Distância, que tem o objetivo principal de identificar, por meio de uma meta-análise de natureza quantitativa, as causas de abandono na Educação a Distância no Brasil.

A pesquisa buscou classificar as causas de evasão detectadas em diversos cursos da modalidade a distância no país. 


\section{EVASÃO NA EDUCAÇÃO A DISTÂNCIA}

A Educação a Distância no Brasil vem, desde a última década, destacando-se pela capacidade de ampliar e democratizar o acesso à educação, expandindo-se rapidamente com o objetivo de fornecer formação superior e especialização àqueles que por inúmeros motivos não tiveram acesso ao curso presencial (GROSSI; NUNES, 2014; LAHAM; LEMES, 2016).

O crescimento da modalidade de EaD no Brasil é validado pelo censo da Educação Superior de 2018 (ABED, 2019), pois, segundo o Ministério da Educação (MEC), entre o período de 2008 e 2018, o ingresso e as matrículas de alunos em cursos a distância aumentaram 196,6\% e 182,5\% respectivamente.

A partir desse crescimento, os problemas relacionados à modalidade de EaD passam a ter uma maior atenção dos gestores e pesquisadores da área. Para Colpani (2018), por exemplo, é importante que os problemas que ocorrem em projetos de Educação à distância sejam acompanhados e solucionados.

Entre esses problemas, a evasão é uma das principais dificuldades, podendo ser definida de várias formas (MATTAR, 2018; COLPANI, 2018). Para Maia, Meirelles e Pela (2004), a evasão é definida como estudantes que não completaram o curso, incluindo aqueles que se matriculam e desistem antes mesmo de iniciá-lo. Outra definição foi apresentada por Martins et al. (2013), que consideram a evasão como a desistência do aluno em qualquer momento após ter participado da aula inaugural presencial. Neste trabalho adotaremos a definição de Maia, Meirelles e Pela (2004) a fim de abranger uma maior quantidade de estudos.

Por tratar-se de um fenômeno que ocorre globalmente, existente em todos os níveis acadêmicos, e por ser um tema recorrente na área da educação pública e privada, a evasão vem sendo objeto de vários estudos com o objetivo de entender e encontrar as suas causas (PASSOS; BARBOSA; LACERDA, 2020).

Os estudos realizados por Xenos, Pierrakeas e Pintelas (2002) apontam que a dificuldade em administrar o tempo para dedicar aos estudos, a sensação de que o conhecimento adquirido no curso não é suficiente para o nível universitário, a falta de assistência do tutor e os problemas de saúde do aluno, ou de familiares, são os fatores que estão relacionados a evasão.

Para Espíndola e Lacerda (2013), os cursos ministrados a distância possuem características que proporcionam a flexibilidade de tempo e de localização aos alunos, acarretando alguns desafios como a dificuldade em acompanhar as atividades propostas, a necessidade de proatividade e os problemas relacionados com o uso da tecnologia. Em seu estudo, o autor ainda apresenta que a maior parte das evasões ocorrem nos períodos iniciais, relacionando-as aos fatores como ingresso em outro curso superior, a falta de compatibilidade do aluno com o curso e os problemas pessoais que apareceram no decorrer do curso.

Ainda nesse contexto, Silva Filho et al. (2007) observam que as evasões geram problemas sociais, acadêmicos e econômicos, uma vez que, para o setor público, os investimentos não têm retorno, e para o setor privado ocorrem perdas de receitas. Ainda de acordo com Silva Filho et al. (2007) poucas instituições de Ensino Superior possuem programas planejados para o combate à evasão. 
Segundo Castro (2001), a revisão sistemática é planejada para responder a uma pergunta específica, utilizando métodos explícitos e sistemáticos para identificar, selecionar e avaliar criticamente os estudos, bem como para coletar e analisar os dados desses estudos incluídos na pesquisa.

A metodologia adotada neste estudo foi adaptada do Guia Para Realizar Uma Revisão Sistemática de Literatura (OKOLI, 2019).

A realização desta revisão foi dividida em sete etapas: planejamento; busca; seleção; avaliação; extração de dados; síntese e redação.

No planejamento, o objetivo da pesquisa e os passos seguintes da revisão foram apresentados aos participantes, que também puderam discutir e alinhar os procedimentos de cada etapa. Além da discussão inicial sobre as atividades a serem desenvolvidas, a cada nova etapa, os participantes revisaram o que deveria ser realizado para manter o rigor necessário à revisão sistemática da literatura.

O objetivo da pesquisa foi identificar as causas da evasão na Educação a Distância no Brasil. Para isso, a revisão buscou artigos que abordassem as causas da evasão na EaD em alguma instituição de ensino do país.

A etapa de busca foi dividida em 2 partes. Na primeira parte, as buscas foram feitas diretamente em 12 periódicos especializados em Educação a Distância listados no Qualis Periódicos da Plataforma Sucupira - pertencente à CAPES -, no quadriênio 2013-2016 com as áreas de avaliação definidas em ensino e educação.

Em cada periódico, na data de 15 de abril de 2020, as buscas foram realizadas com os termos "evasão", "desistência" e "abandono". Ao total, as buscas retornaram 76 artigos com essas palavras-chave.

A partir de uma avaliação geral preliminar dos artigos encontrados, em 30 artigos de interesse à pesquisa, procurou-se termos e palavras-chaves em comum que pudessem validar as próximas buscas em bases de dados gerais. Ambos os termos, "evasão" e "educação a distância", foram encontrados em $52 \%$ dos artigos de interesse.

Assim, o segundo momento das buscas foi realizado em $1^{\circ}$ de junho de 2020 , no Portal de Periódicos CAPES, utilizando o termo conjunto de busca "evasão E educação a distância". Essas buscas retornaram 123 artigos, dos quais 12 já tinham sido encontrados nas primeiras buscas em periódicos específicos em Educação a Distância. Assim sendo, ao todo foram encontrados 181 artigos que passaram à fase de seleção.

Para a seleção observou-se os resumos dos artigos que abordavam a evasão na EaD em alguma instituição de ensino no Brasil. Consequentemente, foram selecionados 69 artigos.

$\mathrm{Na}$ etapa seguinte, os artigos foram avaliados para participação na etapa de extração dos dados a partir dos critérios a seguir: (1) o estudo deveria apresentar as causas de evasão identificadas; (2) as causas de evasão apresentadas nos estudos não poderiam ser concluídas a partir de revisões da literatura; (3) o estudo deveria ter sido realizado em alguma instituição de ensino do Brasil.

Após a avaliação, identificou-se 40 artigos que atendiam a todos os critérios pré-definidos para a análise dos dados. A extração dos dados foi realizada por meio de formulários que 
buscaram capturar as informações descritas a seguir: (i) Identificação do artigo - numeração atribuída a cada artigo selecionado para a revisão; (ii) Causa da evasão - lista das causas de evasão apresentadas no estudo; (iii) Tipo de evasão - sem especificação, evasão em qualquer momento durante o curso, evasão após a primeira aula ou a primeira avaliação; (iiii) Tipo de instituição privada, pública municipal, pública estadual, pública federal, mais de um tipo de instituição; (iiiii) Grau de ensino - livre, técnico, superior, especialização, não especificado.

Os dados extraídos passaram por uma meta-análise que realizou classificações e agrupamentos das causas de evasão de acordo com o que já foi proposto em outros trabalhos (LAHAM; LEMES, 2016; BITTENCOURT; MERCADO, 2014; XENOS; PIERRAKEAS; PINTELAS, 2002).

A síntese dos resultados da meta-análise é apresentada na seção seguinte deste artigo.

\section{RESULTADOS}

Segundo Laham e Lemes (2016), Bittencourt e Mercado (2014) e Xenos, Pierrakeas e Pintelas (2002), as causas de evasão podem ser categorizadas em causas endógenas e causas exógenas. As causas exógenas são aquelas que os fatores são externos à instituição de ensino ou curso; as endógenas se relacionam diretamente com a instituição de ensino ou o curso em questão (LAHAM; LEMES, 2016).

A partir dessas definições e baseado nos estudos de Bittencourt e Mercado (2014) e Carvalho, Almeida e Cavalcanti (2018), no presente estudo, as causas exógenas foram divididas em 5 grupos e 14 subgrupos e as endógenas em 4 grupos e 6 subgrupos. Os Quadros 1 e 2 apresentam as divisões propostas pelos autores.

\section{Quadro 1: Causas de evasão exógenas}

\begin{tabular}{|c|c|c|c|}
\hline Grupo & Descrição do Grupo & Subgrupo & Descrição do subgrupo \\
\hline \multirow[t]{2}{*}{$\begin{array}{l}\text { Falta de } \\
\text { Tempo }\end{array}$} & \multirow[t]{2}{*}{$\begin{array}{l}\text { São os fatores que decorrem } \\
\text { do aluno não conseguir } \\
\text { adequar as atividades } \\
\text { pessoais, profissionais e as } \\
\text { relacionadas ao curso } \\
\text { (BITTENCOURT; MERCADO, } \\
\text { 2014) }\end{array}$} & Trabalho & $\begin{array}{l}\text { Preservando os termos usados por } \\
\text { Bittencourt e Mercado (2014): } \\
\text { Carga horária semanal de trabalho; } \\
\text { adequação do conteúdo com o } \\
\text { trabalho; apoio da instituição onde } \\
\text { trabalha. }\end{array}$ \\
\hline & & $\begin{array}{l}\text { Organização } \\
\text { pessoal }\end{array}$ & $\begin{array}{l}\text { Tempo para estudar; possuir outro } \\
\text { curso superior; adaptação ao sistema } \\
\text { universitário; dificuldade de assimilação } \\
\text { da cultura de EaD. (BITTENCOURT; } \\
\text { MERCADO, 2014). }\end{array}$ \\
\hline \multirow[t]{2}{*}{$\begin{array}{l}\text { Contexto } \\
\text { familiar }\end{array}$} & \multirow{2}{*}{$\begin{array}{l}\text { São fatores que não } \\
\text { dependem da condição dos } \\
\text { alunos (BITTENCOURT; } \\
\text { MERCADO, 2014). } \\
\end{array}$} & \begin{tabular}{|l|} 
Problemas \\
familiares
\end{tabular} & $\begin{array}{l}\text { Influência familiar (BITTENCOURT; } \\
\text { MERCADO, 2014). }\end{array}$ \\
\hline & & $\begin{array}{l}\text { Mudança de } \\
\text { estado civil }\end{array}$ & $\begin{array}{l}\text { Mudança de estado civil (BITTENCOURT, } \\
\text { MERCADO, 2014). }\end{array}$ \\
\hline $\begin{array}{l}\text { Acesso à } \\
\text { internet }\end{array}$ & $\begin{array}{l}\text { O fator se relaciona com a } \\
\text { condição socioeconômica do } \\
\text { aluno. (BITTENCOURT; } \\
\text { MERCADO, 2014) } \\
\end{array}$ & $\begin{array}{l}\text { Pouco ou } \\
\text { nenhum } \\
\text { acesso à } \\
\text { internet }\end{array}$ & $\begin{array}{l}\text { Dificuldades de acesso à internet } \\
\text { (BITTENCOURT; MERCADO, 2014) }\end{array}$ \\
\hline
\end{tabular}




\begin{tabular}{|c|c|c|c|}
\hline Grupo & Descrição do Grupo & Subgrupo & Descrição do subgrupo \\
\hline \multirow{3}{*}{$\begin{array}{l}\text { Problemas } \\
\text { com os } \\
\text { professores } \\
\text { ou tutores }\end{array}$} & \multirow{3}{*}{$\begin{array}{l}\text { São fatores que decorrem do } \\
\text { isolacionismo do aluno e da } \\
\text { ausência de contato pessoal } \\
\text { entre alunos e/ou professores } \\
\text { (EMANUELLI, 2012). }\end{array}$} & $\begin{array}{l}\text { Baixa } \\
\text { interação com } \\
\text { os tutores }\end{array}$ & $\begin{array}{l}\text { Contato com professores } \\
\text { (BITTENCOURT; MERCADO, 2014). }\end{array}$ \\
\hline & & \begin{tabular}{|l|} 
Baixa \\
interação com \\
outros \\
docentes \\
\end{tabular} & $\begin{array}{l}\text { Contato entre colegas de cursos } \\
\text { (BITTENCOURT; MERCADO, 2014). }\end{array}$ \\
\hline & & $\begin{array}{l}\text { Problemas } \\
\text { com os } \\
\text { professores }\end{array}$ & $\begin{array}{l}\text { Insatisfação com o tutor (BITTENCOURT; } \\
\text { MERCADO, 2014). }\end{array}$ \\
\hline \multirow[t]{6}{*}{$\begin{array}{l}\text { Condição } \\
\text { pessoal }\end{array}$} & \multirow{6}{*}{$\begin{array}{l}\text { São os fatores relacionados a } \\
\text { problemas de ordem pessoal } \\
\text { do aluno (CARVALHO; } \\
\text { ALMEIDA; CAVALCANTI, 2018) } \\
\text { e sua adequação ao curso. }\end{array}$} & Saúde & $\begin{array}{l}\text { Problemas de saúde (BITTENCOURT; } \\
\text { MERCADO, 2014) }\end{array}$ \\
\hline & & $\begin{array}{l}\text { Problemas } \\
\text { pessoais }\end{array}$ & $\begin{array}{l}\text { Problemas de ordem pessoal } \\
\text { (CARVALHO; ALMEIDA; CAVALCANTI, } \\
\text { 2018) }\end{array}$ \\
\hline & & $\begin{array}{l}\text { Educação } \\
\text { básica } \\
\text { ineficiente }\end{array}$ & $\begin{array}{l}\text { Deficiências acumuladas ao longo da } \\
\text { Educação Básica (CARVALHO; ALMEIDA; } \\
\text { CAVALCANTI, 2018) }\end{array}$ \\
\hline & & \begin{tabular}{|l|} 
Condição \\
financeira \\
\end{tabular} & $\begin{array}{l}\text { Dificuldades financeiras (CARVALHO; } \\
\text { ALMEIDA; CAVALCANTI, 2018) }\end{array}$ \\
\hline & & Mobilidade & $\begin{array}{l}\text { Deslocamento até o polo presencial } \\
\text { (CARVALHO; ALMEIDA; CAVALCANTI, } \\
\text { 2018) }\end{array}$ \\
\hline & & $\begin{array}{l}\text { Desmotivação } \\
\text { ou } \\
\text { desinteresse }\end{array}$ & $\begin{array}{l}\text { Insatisfação com o curso; falta de } \\
\text { perspectiva de trabalho; falta de } \\
\text { interesse; e desânimo para a conclusão; } \\
\text { modificação do interesse pessoal ou } \\
\text { profissional. (CARVALHO; ALMEIDA; } \\
\text { CAVALCANTI, 2018; BITTENCOURT; } \\
\text { MERCADO, 2014) }\end{array}$ \\
\hline
\end{tabular}

Fonte: Elaborado pelos autores com base na pesquisa realizada.

Quadro 2: Causas de evasão endógenas

\begin{tabular}{|c|c|c|c|}
\hline Grupo & $\begin{array}{l}\text { Descrição do } \\
\text { Grupo }\end{array}$ & Subgrupo & Descrição do subgrupo \\
\hline \multirow[t]{2}{*}{$\begin{array}{l}\text { Dificuldades } \\
\text { acadêmicas }\end{array}$} & \multirow{2}{*}{$\begin{array}{l}\text { São os } \\
\text { fatores que } \\
\text { decorrem de } \\
\text { aspectos } \\
\text { acadêmicos e } \\
\text { institucionais } \\
\text { do curso ou } \\
\text { da instituição } \\
\text { (CARVALHO; } \\
\text { ALMEIDA; } \\
\text { CAVALCANTI, } \\
\text { 2018) }\end{array}$} & $\begin{array}{l}\text { Problemas } \\
\text { com atividades } \\
\text { e avaliações }\end{array}$ & $\begin{array}{l}\text { Reprovação em disciplinas; tempo de respostas ou } \\
\text { correção das atividades propostas; conteúdos das } \\
\text { disciplinas; quantidade de disciplinas cursadas } \\
\text { simultaneamente; critérios de avaliação; grau de } \\
\text { complexidade das atividades; exigência de provas } \\
\text { ou atividades presenciais; dificuldade de } \\
\text { assimilação da formação prática com a teórica. } \\
\text { (CARVALHO; ALMEIDA; CAVALCANTI, 2018) }\end{array}$ \\
\hline & & $\begin{array}{l}\text { Problemas } \\
\text { com o material } \\
\text { didático }\end{array}$ & $\begin{array}{l}\text { O material didático fornecido (BITTENCOURT; } \\
\text { MERCADO, 2014) }\end{array}$ \\
\hline
\end{tabular}




\begin{tabular}{|c|c|c|c|}
\hline Grupo & $\begin{array}{l}\text { Descrição do } \\
\text { Grupo }\end{array}$ & Subgrupo & Descrição do subgrupo \\
\hline Uso da plataforma & & $\begin{array}{l}\text { Dificuldades } \\
\text { com a gestão } \\
\text { ou utilização } \\
\text { da plataforma }\end{array}$ & $\begin{array}{l}\text { Estrutura e organização do ambiente virtual, } \\
\text { instabilidade da plataforma, tecnologia inadequada } \\
\text { utilizada. (DAUDT; BEHAR, 2013; BITTENCOURT; } \\
\text { MERCADO, 2014) }\end{array}$ \\
\hline \multirow[t]{3}{*}{ Gestão do curso } & & $\begin{array}{l}\text { Problemas } \\
\text { estruturais }\end{array}$ & $\begin{array}{l}\text { Infraestrutura do polo; problemas administrativos; } \\
\text { gestão da instituição; qualidade do curso ofertado; } \\
\text { falha na elaboração do curso. (CARVALHO; } \\
\text { ALMEIDA; CAVALCANTI, 2018; MEZZARI et al., 2013; } \\
\text { BITTENCOURT; MERCADO, 2014) }\end{array}$ \\
\hline & & $\begin{array}{l}\text { Fornecimento } \\
\text { de } \\
\text { informações } \\
\text { prévias }\end{array}$ & $\begin{array}{l}\text { Desconhecimento prévio do funcionamento da } \\
\text { modalidade e/ou do curso; informações imprecisas } \\
\text { sobre o curso; falsa expectativa de facilidade do } \\
\text { curso à distância. (CORNÉLIO; WASNER } \\
\text { VASCONCELOS, 2015; BERTOLUCI; SOUZA JUNOR; } \\
\text { RODRIGUES, 2018) }\end{array}$ \\
\hline & & $\begin{array}{l}\text { Apoio aos } \\
\text { estudantes }\end{array}$ & $\begin{array}{l}\text { Apoio dos professores e tutores; apoio da } \\
\text { coordenação do curso; apoio dos professores do } \\
\text { polo presencial; motivação e incentivo do tutor. } \\
\text { (CARVALHO; ALMEIDA; CAVALCANTI, 2018; } \\
\text { BITTENCOURT; MERCADO, 2014). }\end{array}$ \\
\hline
\end{tabular}

Fonte: Elaborado pelos autores com base na pesquisa realizada.

Considerando os agrupamentos propostos nos Quadros 1 e 2, as causas da evasão citadas nos estudos foram quantificadas conforme os Quadros 3 e 4.

Quadro 3: Frequência de citações das causas exógenas nas publicações revisadas

\begin{tabular}{|c|c|c|c|c|c|}
\hline Grupo & $\begin{array}{c}\text { Quantidade } \\
\text { de artigos por } \\
\text { grupo }\end{array}$ & $\begin{array}{l}\text { Quantidade de } \\
\text { artigos por } \\
\text { grupo (\%) }\end{array}$ & Subgrupo & $\begin{array}{c}\text { Quantidade } \\
\text { de artigos } \\
\text { por } \\
\text { subgrupo }\end{array}$ & $\begin{array}{l}\text { Quantidade } \\
\text { de artigos } \\
\text { por } \\
\text { subgrupo } \\
(\%)\end{array}$ \\
\hline \multirow[t]{2}{*}{ Falta de tempo } & \multirow[t]{2}{*}{32} & \multirow[t]{2}{*}{$80 \%$} & Trabalho & 18 & $45 \%$ \\
\hline & & & Organização pessoal & 20 & $50 \%$ \\
\hline \multirow{2}{*}{$\begin{array}{l}\text { Contexto } \\
\text { familiar }\end{array}$} & \multirow[t]{2}{*}{11} & \multirow[t]{2}{*}{$27,5 \%$} & Problemas familiares & 10 & $25 \%$ \\
\hline & & & Mudança de estado civil & 1 & $2,5 \%$ \\
\hline $\begin{array}{l}\text { Acesso à } \\
\text { internet }\end{array}$ & 4 & $10 \%$ & $\begin{array}{l}\text { Pouco ou nenhum } \\
\text { acesso à internet }\end{array}$ & 4 & $10 \%$ \\
\hline \multirow{3}{*}{$\begin{array}{l}\text { Problemas com } \\
\text { tutores ou } \\
\text { professores }\end{array}$} & \multirow[t]{3}{*}{15} & \multirow[t]{3}{*}{$37,5 \%$} & $\begin{array}{l}\text { Baixa interação com os } \\
\text { tutores }\end{array}$ & 7 & $17,5 \%$ \\
\hline & & & $\begin{array}{l}\text { Baixa interação com } \\
\text { outros docentes }\end{array}$ & 8 & $20 \%$ \\
\hline & & & $\begin{array}{l}\text { Problemas com os } \\
\text { professores }\end{array}$ & 4 & $10 \%$ \\
\hline \multirow{6}{*}{$\begin{array}{l}\text { Condição } \\
\text { pessoal }\end{array}$} & \multirow[t]{6}{*}{30} & \multirow[t]{6}{*}{$75 \%$} & Saúde & 8 & 20 \\
\hline & & & Problemas pessoais & 16 & $40 \%$ \\
\hline & & & $\begin{array}{l}\text { Educação Básica } \\
\text { ineficiente }\end{array}$ & 3 & $7,5 \%$ \\
\hline & & & Mobilidade & 6 & $15 \%$ \\
\hline & & & Condição financeira & 10 & $25 \%$ \\
\hline & & & $\begin{array}{l}\text { Desmotivação ou } \\
\text { Desinteresse }\end{array}$ & 13 & $32,5 \%$ \\
\hline
\end{tabular}

Fonte: Elaborado pelos autores com base na pesquisa realizada. 
No Quadro 3, podemos observar que a falta de tempo e as condições pessoais são as principais causas exógenas da evasão, sendo citada por $80 \%$ e $75 \%$ dos artigos analisados, respectivamente. A frequência de citações relacionadas ao trabalho e à organização pessoal corroboram com os relatos que os estudantes têm dificuldades em organizar seu tempo de estudo; a organização pessoal e a proatividade são características fundamentais ao estudante da EaD, uma vez que, de acordo com Gottardi (2015), na modalidade a distância, espera-se que o aluno organize seu próprio tempo e estilo de estudo.

Ainda considerando as causas exógenas, as condições pessoais dos alunos foram apontadas em $75 \%$ dos artigos selecionados, sendo os problemas pessoais os mais frequentes, o que corrobora com o estudo realizado por Espíndola e Lacerda (2013) no qual os problemas de ordem pessoais surgidos durante o curso foram determinantes para a não conclusão do curso. 0 segundo fator mais citado foi o desinteresse dos alunos no curso à distância, considerando os estudos de Espíndola e Lacerda (2013) e Rodrigues et al. (2018), o aluno estudar em um curso que deseja e se comprometer com os estudos é fundamental para a conclusão do curso à distância.

Permanecendo no que tange às condições pessoais do discente, presente em 10 dos artigos selecionados - terceiro fator mais frequente - a condição financeira dos discentes também tem grande influência na conclusão do curso EaD, o que confirma os resultados obtidos por Silva (2019), que identificou os problemas financeiros que ocorreram ao longo do curso como o maior fator de evasão.

Apesar de aparecerem em menor frequência, as condições pessoais como a saúde, a mobilidade e a Educação Básica ineficiente também são fatores que influenciam na evasão na EaD. Os problemas de saúde, de acordo com os estudos feitos por Almeida et al. (2013), dentre os quais o descontrole emocional e o uso de medicamentos, contribuíram para a evasão de discentes. Outra problemática apontada pelos artigos selecionados, apesar dos cursos serem ministrados a distância, são as condições de deslocamento e mobilidade do aluno, que influencia nas chances do estudante não concluir o curso. Essa observação está em consonância com o trabalho recente de Pedrosa e Nunes (2019) em que 47\% dos discentes perguntados tinham dificuldades de deslocamento até o polo presencial. Por fim, a Educação Básica ineficiente, apontada por $7,5 \%$ dos artigos, configura-se como uma problemática que pode influenciar negativamente na conclusão do curso, uma vez que essas deficiências podem colaborar para não compreensão de conteúdos e atividades, o que enfatiza os resultados do estudo de Abadi e Rehfeldt (2016), que apresenta as deficiências de conteúdos básicos - pré-requisitos para a Educação Superior - como indicadores de evasão.

Por sua vez, sendo uma causa exógena ao curso, a baixa interação com os tutores e professores, bem como o contexto familiar também aparecem como fatores importantes a serem considerados; os tutores e professores são fundamentais para o sucesso de um curso EaD, pois instigam a participação do acadêmico e possibilita a participação coletiva (OLIVEIRA, 2013). Além disso, são essenciais para o apoio didático e pedagógico aos alunos, portanto se faz necessário que o tutor seja flexível, motive os alunos e potencialize os processos de aprendizagem e ensino (OLIVEIRA, 2013). Diante dos resultados obtidos, uma boa relação entre tutor e aluno é fundamental para a conclusão do curso. 
Quadro 4: Frequência de citações das causas endógenas nas publicações revisadas

\begin{tabular}{|l|c|c|l|c|c|}
\hline Grupo & $\begin{array}{c}\text { Quantidade de } \\
\text { artigos por } \\
\text { grupo }\end{array}$ & $\begin{array}{c}\text { Quantidade de } \\
\text { artigos por } \\
\text { grupo (\%) }\end{array}$ & $\begin{array}{l}\text { Subgrupo } \\
\text { Quantidade }\end{array}$ & $\begin{array}{c}\text { Quantidade de } \\
\text { de artigos } \\
\text { por subgrupo }\end{array}$ & $\begin{array}{c}\text { artigos por } \\
\text { subgrupo (\%) }\end{array}$ \\
\hline $\begin{array}{l}\text { Dificuldades do } \\
\text { curso }\end{array}$ & 21 & $52,5 \%$ & $\begin{array}{l}\text { Problemas com } \\
\text { atividades e } \\
\text { avaliações }\end{array}$ & 18 & $45 \%$ \\
\cline { 2 - 6 } & & $37,5 \%$ & $\begin{array}{l}\text { Problemas com o } \\
\text { material didático }\end{array}$ & 7 & $17,5 \%$ \\
\hline $\begin{array}{l}\text { Uificuldades com } \\
\text { a gestão ou } \\
\text { plataforma } \\
\text { utilização da } \\
\text { plataforma }\end{array}$ & 15 & $37,5 \%$ \\
\hline $\begin{array}{l}\text { Gestão do } \\
\text { curso }\end{array}$ & 15 & $47,5 \%$ & $\begin{array}{l}\text { Problemas } \\
\text { estruturais }\end{array}$ & 10 & $25 \%$ \\
\hline & 19 & $\begin{array}{l}\text { Fornecimento de } \\
\text { informações } \\
\text { prévias }\end{array}$ & 4 & $10 \%$ \\
\hline & & $\begin{array}{l}\text { Apoio aos } \\
\text { estudantes }\end{array}$ & 10 & $25 \%$ \\
\hline
\end{tabular}

Fonte: Elaborado pelos autores com base na pesquisa realizada.

Entre as causas endógenas, podemos observar que a gestão do curso, os problemas com as atividades, as avaliações e o material didático são as causas que mais aparecem nos estudos. Os problemas relacionados aos materiais didáticos e a plataforma colaboram com as evidências encontradas pelos estudos de Souza Júnior e Rodrigues (2018), que relacionam a evasão ao design e orientam sobre os cuidados que os cursos EaD devem ter com o design técnico e estético. Além desse estudo, Lotthammer, Silva e Ferenhof (2018) destacam a importância fundamental do design instrucional, pois é um fator que influencia na motivação dos estudantes devido à relação existente entre a metodologia, a organização e o material didático.

Santos (2017) afirma que, por mais que o material seja construído de uma forma clara, com uma linguagem simples, o estudante precisa ser acolhido e saber que pode contar com professores, tutores e colegas durante o curso. Essa observação compreende bem a importância do apoio do corpo docente, apontado por $25 \%$ dos estudos revisados como uma causa de evasão. Assim, se faz necessário que as instituições prestem um atendimento de qualidade ao professor, pois este é a peça-chave para o sucesso do curso e quando está bem informado e bem atendido pela instituição, possui a segurança necessária para ministrar aulas de forma a atender às expectativas dos estudantes (SARTÓRIO; JUNG; SILVA, 2019).

Dessa forma, a gestão do curso também se destaca como uma causa endógena relevante, pois $47,5 \%$ dos estudos revisados citaram os problemas estruturais, a falta de informação prévia sobre o curso ou sobre a instituição e o apoio deficitário do corpo docente.

Nas instituições de ensino, a gestão do curso deve ser realizada com foco na qualidade do ensino prestado, pois é o diferencial competitivo que interfere na manutenção e combate a evasão. Do mesmo modo, é importante atender as expectativas dos estudantes, pois o entendimento dessas expectativas favorece o planejamento estratégico que serve para direcionar as metas e objetivos do curso (GALVÃO; SADOYAMA, 2017). 


\section{CONCLUSÃO}

Este artigo apresentou os resultados de uma revisão sistemática da literatura sobre as causas da evasão da Educação a Distância no Brasil. A revisão identificou as causas de evasão, que foram classificadas como exógenas e endógenas. Considerando a frequência quantitativa das ocorrências, a principal causa exógena apontada na revisão dos estudos foi a falta de tempo, seguida pelas condições pessoais, os problemas com tutores ou professores, o contexto familiar e, por fim, o acesso à internet. As causas endógenas apresentaram-se de forma similar nas quantidades de citações, sendo as principais: as dificuldades do curso, a gestão do curso e o uso da plataforma tecnológica para a Educação a Distância.

A partir da identificação dos dados, podemos apontar fatores indutores da evasão na modalidade a distância, relacionados às questões do gradativo desinteresse pelo curso, interferências das relações familiares nos estudos, expectativa frustrada de aprendizagem, e ausência de pertencimento institucional, especialmente, o acompanhamento dos atores no processo de aprendizagem, previstos na gestão do curso.

Outros fatores relevantes a serem considerados dizem respeito ao mercado de trabalho e à área de formação escolhida. As licenciaturas, por exemplo, são fortemente marcadas pela precarização do trabalho docente, isso influencia na expectativa sócioprofissional do acadêmico, contribuindo de maneira significativa na evasão.

Destarte, o estudo aponta que é necessário um processo contínuo de autoavaliação no curso, em especial, das atribuições dos atores do processo e da gestão do vínculo semestral dos acadêmicos em curso, sobretudo o acompanhamento do ensino aprendizagem e as melhorias contínuas de processos entre os atores na modalidade a distância, a fim de se evitar a evasão.

Importante considerar o surgimento da pandemia provocada pelo novo coronavírus (SARSCOV2/COVID-19), pois deu notoriedade a educação mediada por tecnologias que é diferente da Educação a Distância. Desta maneira o ensino remoto está sendo utilizado em diferentes níveis de ensino, destacando-se na Educação Básica, todavia é importante considerar que a discussão de evasão, para ambos os casos, exigem estudos mais aprofundados em tempos de pandemia. Por isso, é importante destacar o cuidado que as instituições precisam ter para aprimorar essa modalidade de ensino. $\mathrm{O}$ aprimoramento passa pelo devido cuidado, gestão de processos, no que diz respeito a evasão dos estudantes. Assim, este artigo apresenta e chama atenção às causas de evasão da EaD, sendo uma fonte de informação para o planejamento e gestão desses cursos ofertados pelas instituições de ensino do país.

\section{REFERÊNCIAS}

ABADI, A. M.; REHFELDT, M. J. H. Autonomia para aprendizagem: uma relação entre o fracasso e o sucesso dos alunos da Educação a Distância. Praxis Educativa, Ponta Grossa, v. 11, n. 2, p. 310-331, jun. 2016. Disponível em: https://dialnet.unirioja.es/servlet/articulo?codigo=5513469. Acesso em: 12 jul. 2020.

ASSOCIAÇÃO BRASILEIRA DE EDUCAÇÃO A DISTÂNCIA (ABED). Censo EAD.BR: relatório analítico da aprendizagem a distância no Brasil 2018. Curitiba: InterSaberes, 2019. Disponível em: http://abed.org.br/arquivos/CENSO_DIGITAL_EAD_2018_PORTUGUES.pdf. Acesso em: 12 jul. 2020. 
ALMEIDA, O. C. S. et al. Evasão em cursos a distância: fatores influenciadores. Revista Brasileira de Orientação Profissional, Campinas, v. 14, n. 1, p. 19-33, jun. 2013. Disponível em: http://pepsic.bvsalud.org/scielo.php?script=sci_arttext\&pid=S1679-33902013000100004. Acesso em: 12 jul. 2020.

AMORIM, M. J. V.; BARONE, D.; MANSUR, A. U. Técnicas de Aprendizado de Máquina Aplicadas na Previsão de Evasão Acadêmica. Brazilian Symposium on Computers in Education (Simpósio Brasileiro de Informática na Educação - SBIE), Porto Alegre, p. 666-674, nov. 2008. Disponível em: https://www.brie.org/pub/index.php/sbie/article/view/755. Acesso em: 12 jul. 2020.

ASHBY, A. Monitoring student retention in the Open University: definition, measurement, interpretation and action. Open Learning: The Journal of Open, Distance and e-Learning, v. 19, n. 1, p. 65-77, fev. 2004. Disponível em: https://www.tandfonline.com/doi/abs/10.1080/0268051042000177854. Acesso em: 12 jul. 2020.

BALTAR, P. C.; SILVA, S. S. Um olhar acerca da evasão na Educação a Distância. Revista UNIABEU, Belford Roxo, v. 10, n. 24, p. 61-73, jan. 2017. Disponível em:

https://revista.uniabeu.edu.br/index.php/RU/article/download/1993/pdf. Acesso em: 12 jul. 2020.

BERTOLUCI, E. A.; SOUZA, A. R. Processos de ensino e aprendizagem de Matemática em um formato híbrido na educação superior. Revista Diálogo Educacional, Curitiba, v. 18, n. 57, 26 jun. 2018. Disponível em: https://periodicos.pucpr.br/index.php/dialogoeducacional/article/view/23835. Acesso em: 12 jul. 2020.

BITTENCOURT, I. M.; MERCADO, L. P. L. Evasão nos Cursos na Modalidade de Educação a Distância: Estudo de Caso do Curso Piloto de Administração da UFAL/UAB. Ensaio: Avaliação e Políticas Públicas em Educação, Rio de Janeiro, v. 22, n. 83, jun. 2014. Disponível em:

https://www.scielo.br/j/ensaio/a/jfVS4MNP3mVcZJjJ6W4vrDy/abstract/?lang=pt. Acesso em: 12 jul. 2020.

BRUNO-FARIA, M. F.; FRANCO, A. L. Causas da evasão em curso de graduação a distância em administração em uma universidade pública federal. Teoria e Prática da Educação, v. 14, n. 3, p. 43-56, set. 2012. Disponível em: https://periodicos.uem.br/ojs/index.php/TeorPratEduc/article/view/18487. Acesso em: 12 jul. 2020.

CARVALHO, P. S. A.; ALMEIDA, E. A.; CAVALCANTI, M. C. M. Análise da evasão na Educação a Distância: um estudo no curso de bacharelado em Administração Pública do IFPB/UAB. Revista Principia, v. 1, n. 41, p. 139-151, jun. 2018. Disponível em: https://periodicos.ifpb.edu.br/index.php/principia/article/view/2126. Acesso em: 12 jul. 2020.

CASTRO A. A. Revisão Sistemática e Meta-análise. Compacta: Temas de Cardiologia, v. 3, n. 1, p. 5-9, 2001. Disponível em: http://www.usinadepesquisa.com/metodologia/wpcontent/uploads/2010/08/meta1.pdf. Acesso em: 30 nov. 2020.

COLPANI, R. Educação a Distância: Identificação dos Fatores que Contribuíram para a Evasão dos Alunos no Curso de Gestão Empresarial da Faculdade de Tecnologia de Mococa. EaD Em Foco, Rio de Janeiro, v. 8, n. 1, ago. 2018. Disponível em: https://eademfoco.cecierj.edu.br/index.php/Revista/article/view/688. Acesso em: 12 jul. 2020.

CORNÉLIO, R. A.; WASNER VASCONCELOS, F. C. Evasão e permanência estudantil na educação a distância. Opción, Venezuela, v. 31, n. 1, p. 204-222, set. 2015. Disponível em: https://www.redalyc.org/pdf/310/31043005012.pdf. Acesso em: 12 jul. 2020. 
DAUDT, S. I. D.; BEHAR, P. A. A gestão de cursos de graduação a distância e o fenômeno da evasão.

Educação, Porto Alegre, v. 36, n. 3, p. 412-421, dez. 2013. Disponível em:

https://revistaseletronicas.pucrs.br/ojs/index.php/faced/article/view/15543. Acesso em: 12 jul. 2020.

EMANUELLI, G. B. Atração e refração na educação a distância: constatações sobre o isolacionismo e a evasão do aluno. Revista Gestão Universitária na América Latina: GUAL, Florianópolis, v. 4, n. 2, p. $205-$ 218, jun. 2012. Disponível em: https://periodicos.ufsc.br/index.php/gual/article/view/1983-

4535.2011v4n2p205. Acesso em: 12 jul. 2020.

ESPÍNDOLA, R. M.; LACERDA, F. K. D. Evasão na Educação a Distância: um estudo de caso. EaD Em Foco, Rio de Janeiro, v. 3, n. 1, jun. 2013. Disponível em:

https://eademfoco.cecierj.edu.br/index.php/Revista/article/view/174. Acesso em: 12 jul. 2020.

GALVÃO, L. L. C.; SADOYAMA, A. S. P. Avaliação da expectativa e percepção da qualidade dos serviços educacionais na perspectiva de gestores, professores e estudantes de um instituto federal do estado de Minas Gerais (MG). Revista EDaPECI, São Cristóvão, SE, v. 17, n. 2, p. 131-143, set. 2017. Disponível em: https://seer.ufs.br/index.php/edapeci/article/view/6275. Acesso em: 12 jul. 2020.

GOTTARDI, M. L. A autonomia na aprendizagem em educação a distância: competência a ser desenvolvida pelo aluno. Revista Brasileira de Aprendizagem Aberta e a Distância, São Paulo, v. 14, mai. 2015. Disponível em: http://seer.abed.net.br/index.php/RBAAD/article/view/268. Acesso em: 12 jul. 2020.

GROSSI, M. G. R.; NUNES, R. C. Comparação entre as características e percepções de alunos em curso e dos evadidos de um curso técnico a distância do IF Fluminense. Revista EDaPECI, São Cristóvão, SE, v. 14, n. 3, p. 470-495, dez. 2014. Disponível em: https://seer.ufs.br/index.php/edapeci/article/view/2346. Acesso em: 12 jul. 2020.

LAHAM, S. A. D.; LEMES, S. S. Um estudo sobre as possíveis causas de evasão em curso de licenciatura em pedagogia a distância. Revista on line de Política e Gestão Educacional, Araraquara, v. 20, n. 3, p. 405431, set./dez. 2016. Disponível em: https://periodicos.fclar.unesp.br/rpge/article/view/9753. Acesso em: 12 jul. 2020.

LIRA, K. C. et al. Utilizando Mineração de Dados e Sistemas Multiagentes na Análise da Evasão em Educação a Distância por meio do Perfil dos Alunos. In: ENCONTRO NACIONAL DE INTELIGÊNCIA ARTIFICIAL E COMPUTACIONAL, 13., Recife, PE, out. 2016. Anais [...].Porto Alegre: SBC, 2016. Disponível em:

https://www.researchgate.net/publication/308995146_Utilizando_Mineracao_de_Dados_e_Sistemas_Mu Itiagentes_na_Analise_da_Evasao_em_Educacao_a_Distancia_por_meio_do_Perfil_dos_Alunos. Acesso em: 12 jul. 2020.

LOTTHAMMER, K. S.; SILVA, J. B.; FERENHOF, H. A. A importância do desenho instrucional para o sucesso de cursos online: uma revisão sistemática. Revista EDaPECI, São Cristóvão, SE, v. 18, n. 2, p. 7-23, ago. 2018. Disponível em: https://seer.ufs.br/index.php/edapeci/article/view/9349. Acesso em: 12 jul. 2020.

MARTINS, C. Z.; GEBRAN, R. A.; TERÇARIOL, A. A. L. A evasão na perspectiva pos alunos: uma análise no curso de administração a distância. In: SIMPÓSIO INTERNACIONAL DE EDUCAÇÃO A DISTÂNCIA, 2014, São Carlos. Anais [....]. São Carlos: UFSCar, 2014. Disponivel em: http://sistemas3.sead.ufscar.br/ojs/index.php/2014/article/download/823/340. Acesso em: 12 jul. 2020.

MARTINS, R. X. et al. Porque eles desistem? Estudo sobre a evasão em cursos de licenciatura a distância. In: CONGRESSO BRASILEIRO DE ENSINO SUPERIOR A DISTÂNCIA, 10., 2013, Belém. Anais [...]. Belém: UNIREDE, 2013. Disponível em: http://repositorio.ufla.br/jspui/handle/1/3127. Acesso em: 12 jul. 2020. 
MATTAR, J. Quais são as iniciativas que ajudam a reduzir as taxas de evasão da EaD? In: ASSOCIAÇÃO BRASILEIRA DE EDUCAÇÃO A DISTÂNCIA (ABED). Censo EAD.BR: Relatório analítico da aprendizagem a distância no Brasil 2017. Curitiba: InterSaberes, 2018. Disponível em: http://abed.org.br/arquivos/CENSO_EAD_BR_2018_digital_completo.pdf. Acesso em: 12 jul. 2020.

MEZZARI, A. et al. Estratégias Para Deteç̧ão Precoce de Propensão à Evasão. RIED: Revista Iberoamericana de Educación a Distancia, Madrid, v. 16, n. 2, p. 147-175, set. 2013. Disponível em: https://www.redalyc.org/pdf/3314/331429869007.pdf. Acesso em: 12 jul. 2020.

OKOLI, C. Guia Para Realizar uma Revisão Sistemática de Literatura. EaD em Foco, Rio de Janeiro, v. 9, n. 1, abr. 2019. Disponível em: https://eademfoco.cecierj.edu.br/index.php/Revista/article/view/748. Acesso em: 12 jul. 2020.

OLIVEIRA, A. M. A. P. O papel do tutor em cursos de educação a distância: competências e habilidades. Revista Multitexto, Montes Claros, v. 2, n. 1, p. 23-29, 2013. Disponível em: http://www.ead.unimontes.br/multitexto/index.php/rmcead/article/view/118. Acesso em: 23 jul. 2020.

PASSOS, M. L. S.; BARBOSA, M. B. A.; LACERDA, L. F. Evasão em cursos técnicos a distância: uma investigação no Programa Profuncionário. Revista EDaPECI, São Cristóvão, SE, v. 20, n. 1, p. 55-65, abr. 2020. Disponível em: https://seer.ufs.br/index.php/edapeci/article/view/11339. Acesso em: 12 jul. 2020.

PEDROSA, R. A.; NUNES, D. O Desafio da Evasão em Cursos Superiores na Modalidade EaD. Revista Paidéi@: Revista Científica de Educação a Distância, Santos, v. 11, n. 1, jul. 2019. Disponível em: https://periodicos.unimesvirtual.com.br/index.php/paideia/article/view/919. Acesso em: 12 jul. 2020.

MAIA, M. C.; MEIRELLES, F. S.; PELA, S. K. Análise dos índices de evasão nos cursos superiores a distância do Brasil. In: CONGRESSO INTERNACIONAL DE EDUCAÇÃO A DISTÂNCIA, 11., 2004, Salvador. Anais [...]. Salvador: ABED, 2004. Disponível em: http://www.abed.org.br/congresso2004/por/htm/073-TC-C2.htm. Acesso em: 12 jul. 2020.

QUEIROGA, E. M. et al. Modelo de Predição da Evasão de Estudantes em Cursos Técnicos a Distância a partir da Contagem de Interações. Revista Thema, Pelotas, v. 15, n. 2, p. 425-438, mai. 2018. Disponível em: http://periodicos.ifsul.edu.br/index.php/thema/article/view/868. Acesso em: 12 jul. 2020.

QUEIROGA, E. M.; CECHINEL, C.; ARAÚJO, R. M. Predição de estudantes com risco de evasão em cursos técnicos a distância. Brazilian Symposium on Computers in Education (Simpósio Brasileiro de Informática na Educação - SBIE), Porto Alegre, p. 1547, out. 2017. Disponível em: https://www.brie.org/pub/index.php/sbie/article/view/7686. Acesso em: 12 jul. 2020.

RIGO, S. J.; BARBOSA, J.; CAMBRUZZI, W. Educação em Engenharia e Mineração de Dados Educacionais: oportunidades para o tratamento da evasão. Revista: EaD \& Tecnologias Digitais na Educação, Dourados, v. 2, n. 3, p. 30-40, jan./nov. 2014. Disponível em: http://ojs.ufgd.edu.br/index.php/ead/article/download/3409/2106. Acesso em: 12 jul. 2020.

RODRIGUES, L. S. et al. A evasão em um curso de especialização em Gestão em Saúde na modalidade a distância. Interface: Comunicação, Saúde, Educação, Botucatu, v. 22, n. 66, p. 889-901, mai. 2018. Disponível em: https://www.scielo.br/j/icse/a/gVbKnFVfvSYvXxn5R65vNzG/?format=pdf\&lang=pt. Acesso em: 12 jul. 2020.

SANTOS, J. C. C. O Impacto do Material Didático Impresso nos Processos de Retenção ou Evasão do Aluno na Modalidade a Distância. Revista Multitexto, Montes Claros, v. 5, p. 45-46, ago. 2017. Disponível em: http://www.ead.unimontes.br/multitexto/index.php/rmcead/article/view/211. Acesso em: 12 jul. 2020. 
SARTÓRIO, M.; JUNG, H. S.; SILVA, L. Q. Qualidade assistencial aos professores de pós-graduação na EaD. Revista EDaPECI, São Cristóvão, SE, v. 19, n. 2, p. 85-95, 6 mai./ago. 2019. Disponível em: https://dialnet.unirioja.es/descarga/articulo/7021741.pdf. Acesso em: 12 jul. 2020.

SILVA FILHO, R. L. L. et al. A evasão no ensino superior brasileiro. Cadernos de Pesquisa, São Paulo, v. 37, n. 132, p. 641-659, set./dez. 2007. Disponível em:

https://www.scielo.br/j/cp/a/x44X6CZfd7hqF5vFNnHhVWg/?lang=pt\&format=pdf. Acesso em: 12 jul. 2020.

SILVA, A. M. Identificação dos aspectos referentes à evasão em cursos de educação à distância nas áreas de Administração e Gestão Financeira. Revista Aprendizagem em EAD, Taguatinga, DF, v. 8, n. 1, ago. 2019. Disponível em: https://portalrevistas.ucb.br/index.php/raead/article/view/8866. Acesso em: 12 jul. 2020.

SOUZA JUNIOR, T. G.; RODRIGUES, G. O. C. A. Design da Sala de Aula Virtual para o Novo Perfil do Aluno de EaD. EaD Em Foco, Rio de Janeiro, v. 8, n. 1, ago. 2018. Disponível em:

https://eademfoco.cecierj.edu.br/index.php/Revista/article/view/698. Acesso em: 12 jul. 2020.

XENOS, M.; PIERRAKEAS, C.; PINTELAS, P. E. A survey on student dropout rates and dropout causes concerning the students in the Course of Informatics of the Hellenic Open University. Computers \& Education, v. 39, n. 4, p. 361-377, dez. 2002. Disponível em:

https://www.researchgate.net/publication/222576796_A_survey_on_student_dropout_rates_and_dropo ut_causes_concerning_the_students_in_the_Course_of_Informatics_of_the_Hellenic_Open_University. Acesso em: 12 jul. 2020. 